\title{
Awareness of disease and risk factors among patients with ischemic heart disease (IHD) in Government general hospital Kurnool, Andhra Pradesh
}

\author{
Prasuna J. \\ (Mrs.Prasuna J., Nursing Tutor, Himalayan College of Nursing, Dehradun. India)
}

\begin{abstract}
Background: Ischemic heart disease among is the most common causes of death and disability in the world. The Indian subcontinent (including India, Pakistan, Bangladesh, Sri Lanka, and Nepal) has among the highest rates of cardiovascular disease (CVD) globally. Previous reports have highlighted the high CVD rates among South Asian immigrants living in Western countries, but the enormous CVD burden within the Indian subcontinent itself has been underemphasized.

Methods: A cross sectional study was conducted at Government General Hospital, Kurnool. Twenty consecutive patients with documented Ischemic Heart disease admitted in Cardiac Care Unit, and Cardiac Ward were enrolled. Patients were interviewed with structured questionnaire enquiring into their awareness of risk factors for Ischemic Heart disease and their knowledge level regarding disease. To assess knowledge and identify risk factors, an in-depth structured interview was conducted with structured interview questionnaire which included 66 questions.

Results: Awareness of risk factors was high for smoking, hypertension, inadequate exercise, stress in family, use of ground nut oil in cooking, A-Type personality and no exercises among patients with ischemic heart disease. A majority 9 (45\%) of patients had average level of knowledge regarding risk factors of Ischemic heart disease, whereas 7 (35\%) of participants had below average and 4 (20\%) had above average level of knowledge.

Conclusion: An Indian population in a hospital setting shows a lack of knowledge relating to modifiable risk factors of ischemic heart disease. By segregating demographic predictors of poor knowledge, such as current smokers and persons who do not exercise regularly, educational interventions can be effectively targeted and executed as primary and secondary prevention strategies to reduce the problem of ischemic heart disease in India.
\end{abstract}

Keyword: Ischemic Heart Disease, Risk factors, Awareness.

\section{Introduction}

In the 1970s, a method for measuring the quality of medical care through identifying "untimely and unnecessary" deaths was proposed ${ }^{1}$.

Many deaths which results from heart disease and stroke can be circumvented through improvements in lifestyle behaviors, treatment of risk factors, and addressing the economic and social conditions that influence the health of individuals and communities. Unhealthy lifestyle behaviors such as tobacco use, inadequate physical activity, poor diet, and excessive alcohol use coupled with uncontrolled hypertension, elevated cholesterol, and obesity account for $80 \%$ of ischemic heart disease mortality in high-income countries such as the United States. Hypertension is the single most important risk factor for stroke, and its control is essential to reduce death from stroke ${ }^{2}$.

The level of awareness of cardiovascular health modifiers among the Indian population has not been clearly quantified. A lack of cardiovascular health knowledge in the general population in neighboring Pakistan is demonstrated by a study in Karachi that reports limited knowledge of modifiable risk factors of heart disease in patients who had experienced an acute myocardial infarction ${ }^{3,4}$. Knowledge of the risk factors is an important step in the modification of lifestyle behaviors conducive to optimal cardiovascular health in developing countries $^{5,6}$

Diabetes, Dyslipidaemia and Hypertension are leading risk factors for coronary heart disease. Global clinical practice guidelines recommend controlling these risk factors as a management strategy to mitigate the 
risk of recurrent heart disease. Henceforth, doctors dealing these patients should emphasis on treating these modifiable risk factors to evidence-based targets ${ }^{7,8}$.

Cardiac diseases are no longer restricted by geographical area or by age, sex, or socioeconomic boundaries. Heart disease has already reached epidemic magnitudes in poorer countries. Of the 45.0 million adult deaths reported worldwide in 2002, three-quarters ( 32 million) were due to noncommunicable diseases. In Southeast Asia alone, 74,23,000 deaths were due to noncommunicable diseases as compared with 57,30,000 deaths related to communicable diseases in the year 2002. Globally, ischemic heart disease (IHD) was the leading killer in the age group $\geq 60$ years, and, with 13,32,000 deaths in adults aged 15-59 years, IHD was ranked behind HIV/AIDS only9.

Patient involvement in the management of their disease, including their effort at reducing and removing any remediable risk factors, is important in the overall treatment strategy. This may be possible if patients were aware of their risk factors and they have appropriate perception of their disease process.

Our study evaluated the knowledge levels of the risk factors among people who were present at Government Hospital Kurnool, Andhra Pradesh. The risk factors included smoking, hypertension, elevated cholesterol levels, DM, and obesity. It was necessary to identify the lacunas in the knowledge of specific risk factors as well as key demographic segments, with significantly poor levels of knowledge pertaining to modifiable risk factors of Ischemic Heart Disease (IHD).

\section{Methods}

Twenty consecutive patients with documented Ischemic Heart disease admitted in Cardiac Care Unit, and Cardiac Ward in Government General Hospital, Kurnool. The enrolled patients were interviewed with structured questionnaire enquiring into their awareness of risk factors for Ischemic Heart disease and their knowledge level regarding disease.A baseline proforma was developed to collect information about age, gender, religion, weight, education, occupation, family income, personal and dietary habit, type of oil consume in cooking, meal pattern and type of personality.

To assess knowledge and identify risk factors, an in-depth structured interview questionnaire was prepared after review of literature. The structured interview questionnaire was divided into five sections with 66 questions. Section-A consists of 23 questions with Yes/No choices related to risk factors of ischemic heart disease. Section B, C, D and E consist of 4, 18, 6, and 15 multiple choice questions to assess the knowledge about general awareness, risk factors, clinical manifestations and prevention of ischemic heart disease, respectively. Content validation was done by experts and reliability was established with split half method for Structured Knowledge Questionnaire ( $\mathrm{r}=0.89$ ). Ethical clearance was obtained from ethical committee; a written informed consent was taken from the participants. The present study was limited with only 20 male or female clients between the age group of 30 to 65 years admitted with ischemic heart disease in Cardiac Care Unit, Cardiology Ward.

\section{Results}

The 20 patients consisted of 13 male (aged $45.45 \pm 11.22$ years) and 7 females (aged $47 \pm 10.87$ years). Almost equal $(35 \%, 30 \%)$ engaged with Cooli and Office work as their occupation whereas, most $(25 \%)$ females were home-maker and very little $(5 \%, 5 \%)$ were cooli and skilled worker. Five patients had never formal education while $6(30 \%)$ were primary education, $5(25 \%)$ intermediate and only $4(20 \%)$ were graduates. It was found that mean weight of 13 male patients $(67.76 \pm 17.62)$ was higher than mean weight of female patients $(59.7 \pm 13.79)$.

Majority, $11(55 \%)$ had below Rs.2000 as monthly family income whereas $4(20 \%)$ patients with Rs. 2000-4000 and $6(30 \%)$ were with Rs. 4000-6000 as their monthly family income. Eighteen patients were nonvegetarian diet and among them 55\% (10/18) were eating chicken and mutton once in a week. (Table 1) 
Table 1: frequency percentage distribution of demographic characteristics of clients with ischemic heart disease

\begin{tabular}{|c|c|c|c|c|}
\hline S.N. & Personal variables & & $\mathbf{N}=\mathbf{2 0}$ & $\%$ \\
\hline \multirow[t]{3}{*}{1.} & Age & $30-40$ & 9 & 45 \\
\hline & & $41-50$ & 6 & 30 \\
\hline & & $51-65$ & 5 & 25 \\
\hline \multirow[t]{2}{*}{2.} & Gender & Male & 13 & 65 \\
\hline & & Female & 7 & 35 \\
\hline \multirow[t]{3}{*}{3.} & Weight & 40-50kgs. & 6 & 30 \\
\hline & & 51-60kgs. & 7 & 35 \\
\hline & & $61 \mathrm{kgs}$ and above & 7 & 35 \\
\hline \multirow[t]{3}{*}{4.} & Religion & Hindu & 11 & 55 \\
\hline & & Muslim & 8 & 40 \\
\hline & & Christian & 1 & 5 \\
\hline \multirow[t]{4}{*}{5.} & Education & Illiterate & 5 & 25 \\
\hline & & Primary & 6 & 30 \\
\hline & & Up to intermediate & 5 & 25 \\
\hline & & Graduation and above & 4 & 20 \\
\hline \multirow[t]{4}{*}{6.} & Occupation & Cooli & 8 & 40 \\
\hline & & Office employee & 5 & 25 \\
\hline & & Skilled work & 2 & 10 \\
\hline & & House maker & 5 & 25 \\
\hline \multirow[t]{2}{*}{7.} & Type of family & Nuclear & 9 & 45 \\
\hline & & Joint & 11 & 55 \\
\hline \multirow[t]{3}{*}{8.} & Income of family & Below 2000/month & 11 & 55 \\
\hline & & $2001-4000 /$ month & 5 & 25 \\
\hline & & 4000 and above & 4 & 20 \\
\hline \multirow[t]{2}{*}{9.} & Type of diet & Vegetarian & 2 & 10 \\
\hline & & Non-vegetarian & 18 & 90 \\
\hline \multirow[t]{3}{*}{10.} & No. of meal/day & Two meals & 1 & 5 \\
\hline & & Three meals & 18 & 90 \\
\hline & & Four and above meals & 1 & 5 \\
\hline
\end{tabular}

Figure 1, Table 2 and 3 shows that awareness of some risk factors was high e.g. Smoking, hypertension, inadequate exercise, stress in family, use of ground nut oil in cooking, A-Type personality and no exercises.

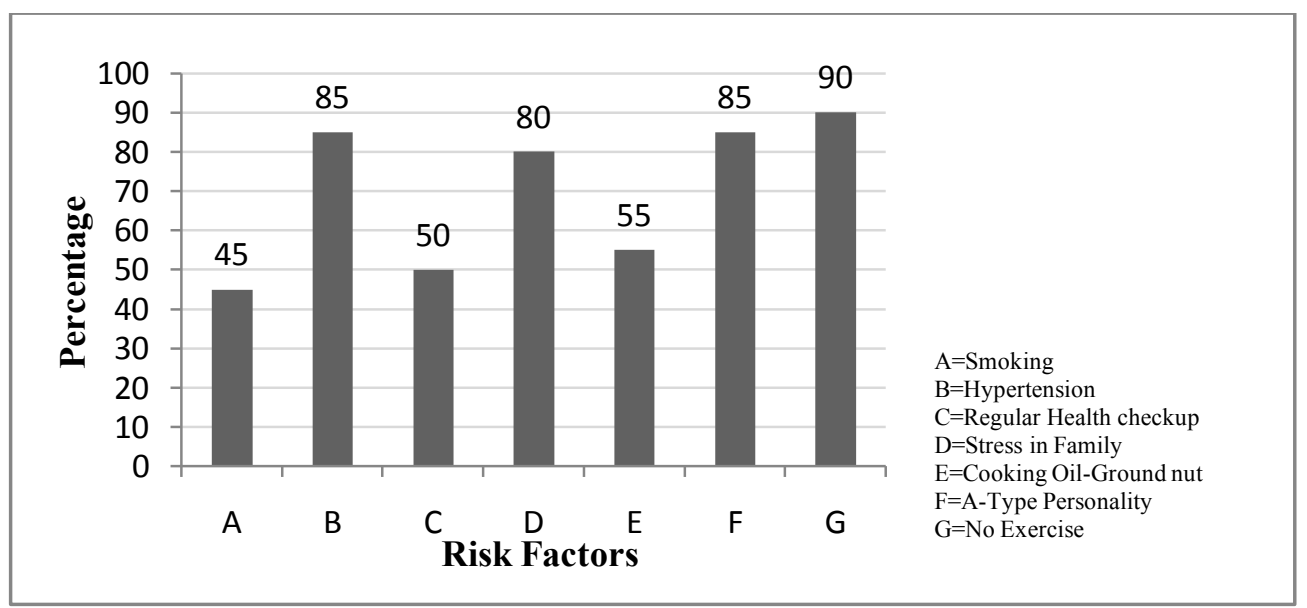

Fig. 1: Awareness of risk factors by the respondents.

Table 2: frequency and percentage distribution of risk factors of clients with Ischemic Heart Disease

\begin{tabular}{clccc}
\hline SN & Personal Habit & $\mathbf{N = 2 0}$ & $\mathbf{\%}$ \\
\hline 1. & Smoking (Cigarette, Beedi) & $9(5+4)$ & 45 \\
\hline 2. & Alcoholism & 3 & 15 \\
\hline 3. & $\begin{array}{l}\text { Types of oil used in } \\
\text { cooking }\end{array}$ & Ground nuts & 11 & 55 \\
\cline { 2 - 4 } & Sun flower & 1 & 5 \\
\hline
\end{tabular}




\begin{tabular}{|c|c|c|c|c|}
\hline & & Palm oil & 5 & 25 \\
\hline & & Refind oil & 3 & 15 \\
\hline \multirow[t]{3}{*}{4.} & \multirow[t]{3}{*}{ Types of personality } & A Type (Aggressive behavior) & 17 & 85 \\
\hline & & B Type (Calm and adjustable & 2 & 10 \\
\hline & & D Type (Depressive behavior) & 1 & 5 \\
\hline 5. & \multicolumn{2}{|c|}{ Diagnosed with hypertension } & 17 & 85 \\
\hline 6. & \multicolumn{2}{|c|}{ Diagnosed with diabetic mellitus } & 5 & 25 \\
\hline 7. & \multicolumn{2}{|c|}{ Experienced the symptoms of IHD } & 11 & 55 \\
\hline 8. & \multicolumn{2}{|l|}{ Family history of IHD } & 5 & 25 \\
\hline 9. & \multicolumn{2}{|c|}{ Absence of regular exercises } & 18 & 85 \\
\hline 10. & \multicolumn{2}{|c|}{ Presence of any stressor in your family } & 11 & 55 \\
\hline 11. & \multicolumn{2}{|c|}{ Live in urban community } & 11 & 55 \\
\hline 12. & \multicolumn{2}{|c|}{ Feel depressed most of the time } & 15 & 75 \\
\hline 13. & \multicolumn{2}{|c|}{ attending regular medication check ups } & 10 & 50 \\
\hline 14. & \multicolumn{2}{|c|}{ admitted in hospital previously } & 11 & 55 \\
\hline
\end{tabular}

The mean knowledge score $(54.8 \pm 11.18)$ was computed. A majority, 9 (45\%) patients had average level of knowledge regarding risk factors of Ischemic heart disease, whereas 7 (35\%) participants had below average and $4(20 \%)$ had above average level of knowledge. (Table 3 \& Fig. 2)

Table 3: Mean Knowledge scores of patients with Ischemic Heart Disease

\begin{tabular}{cclc}
\hline & SD & Range & \multicolumn{1}{c}{ Median } \\
\hline Mean & 11.18 & $35-79$ & 51 \\
\hline 54.8 & & \\
\hline
\end{tabular}

Fig. 2: Knowledge regarding IHD among participants.

Table 4: frequency and percentage distribution of general awareness regarding Ischemic Heart Disease among clients.

\begin{tabular}{|c|c|c|c|c|}
\hline SN & \multicolumn{2}{|c|}{ Knowledge } & $\mathbf{N}=\mathbf{2 0}$ & $\%$ \\
\hline 1. & Ischemic heart disease is a disease of & Heart & 20 & 100 \\
\hline \multirow[t]{4}{*}{2.} & \multirow{4}{*}{ What is meant by Ischemic heart disease } & Increased blood supply to the heart & 3 & 15 \\
\hline & & Reduced blood supply to the heart & 2 & 10 \\
\hline & & Stops the blood supply to the heart & 1 & 5 \\
\hline & & Do not know & 14 & 70 \\
\hline \multirow[t]{3}{*}{3.} & \multirow{3}{*}{ What happens in Ischemic heart disease } & Failure of blood circulation & 2 & 10 \\
\hline & & Infarction & 2 & 10 \\
\hline & & Ischemia & 0 & 0 \\
\hline
\end{tabular}


Awareness of disease and risk factors among patients with ischemic heart disease (IHD) in

\begin{tabular}{|c|c|c|c|c|}
\hline & & All of the above & 0 & 0 \\
\hline & & Do not know & 16 & 80 \\
\hline \multirow[t]{4}{*}{4.} & \multirow{4}{*}{$\begin{array}{l}\text { Ischemic heart disease comes under in } \\
\text { which group }\end{array}$} & Communicable diseases & 2 & 10 \\
\hline & & Non-communicable disease & 17 & 85 \\
\hline & & A \& B & 0 & 0 \\
\hline & & Do not know & 1 & 5 \\
\hline
\end{tabular}

Table 3, indicates that out of 20 clients, $20(100 \%)$ answered IHD is a disease of heart. Regarding meaning of IHD, $3(15 \%)$ answered increased blood supply to the heart, $2(10 \%)$ answered reduced blood supply to the heart, $1(5 \%)$ answered that it stops the blood supply to the heart and $14(70 \%)$ answered that they do not know.

Regarding changes in I.H.D., $2(10 \%)$ answered failure of circulation, $2(10 \%)$ answered infarction and $16(80 \%)$ answered they did not know. Regarding group of I.H.D. to $2(10 \%)$ answered that it is a communicable disease, $17(85 \%)$ answered as non-communicable diseases and only one (5\%) answered that they don't know.

Table 5: Frequency and percentage distribution of knowledge regardingIschemic Heart Disease among patients.

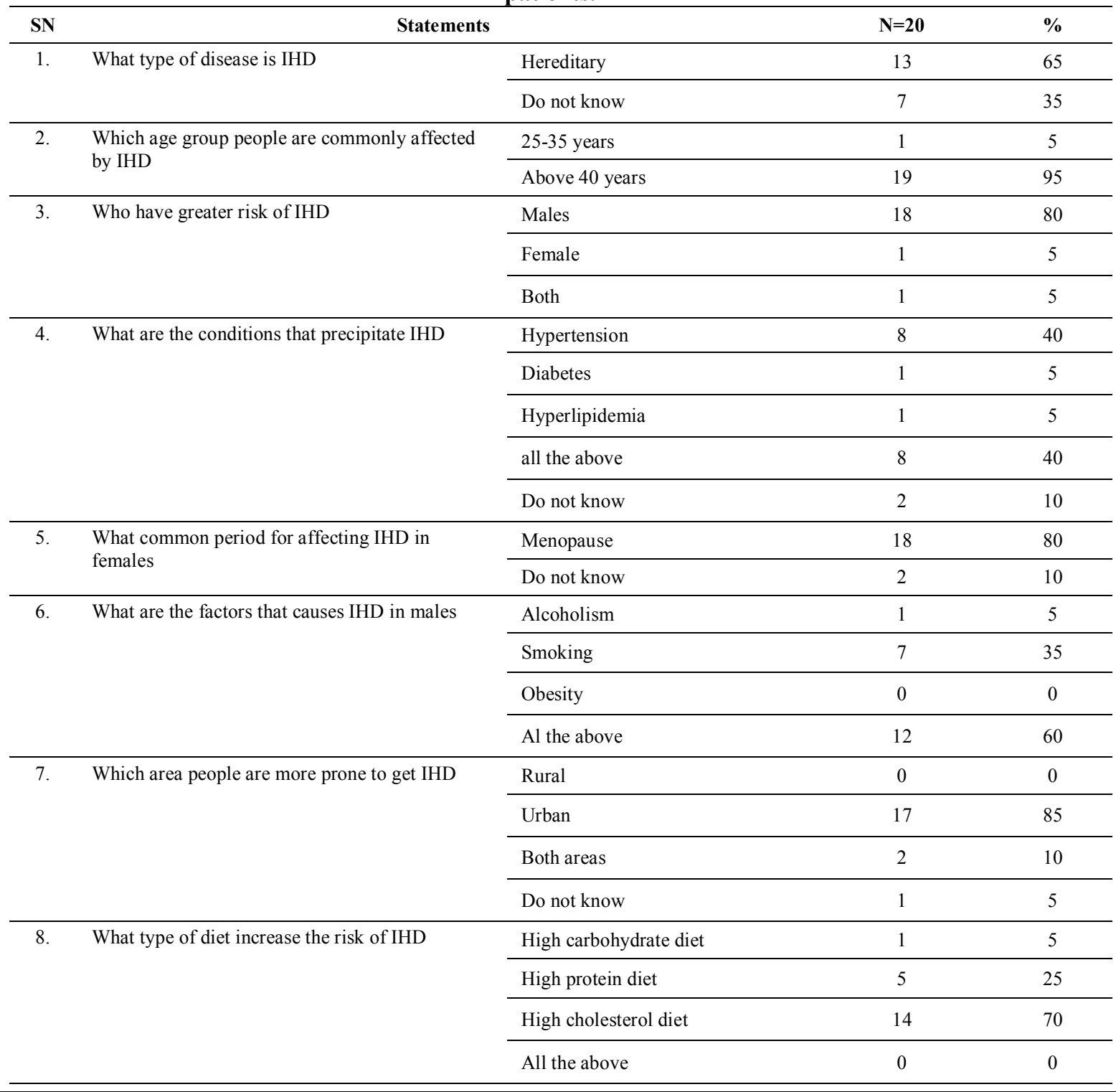




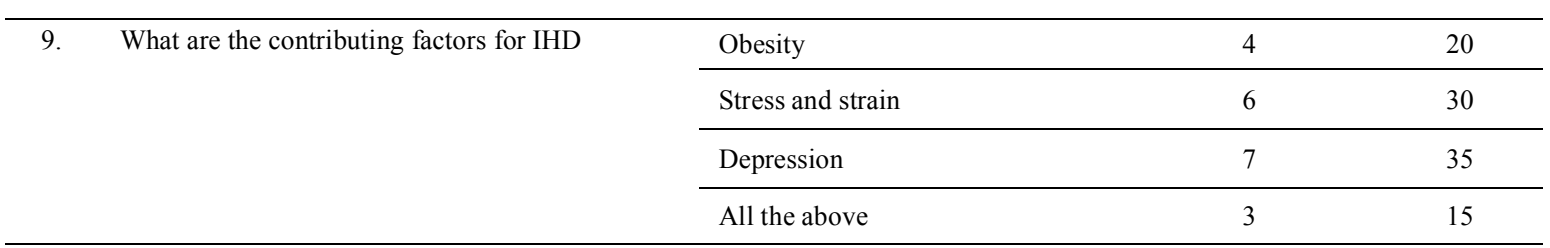

\section{Discussion}

Mostly, 9 (45\%) were between the age group 40 - 50 years, $6(30 \%)$ were between $50-60$ years and 4 $(20 \%)$ were above 60 years of age. Regarding sex of clients $65 \%$ (13) were males, $35 \%$ (7) were females.(other studies $3,4,6,11$. Regarding weight of the client's 30\% (6) were between the $40-50 \mathrm{kgs}$., 35\% (7) were between $51-60 \mathrm{Kgs} ., 35 \%$ (7) were above $60 \mathrm{Kgs}$. of weight. The findings were similar in other studies ${ }^{6}$.

Regarding religion $55 \%$ (11) were Hindus, $40 \%$ (8) were Muslims and only 5\% (1) belonged to Christian. Regarding education $25 \%$ (5) were illiterate, $6(30 \%)$ had primary education, $5(25 \%)$ had intermediate, 4 (20\%) had completed graduation education. ${ }^{11}$

Almost equal, 45\% (9) patients belonged to nuclear family, 55\% (11) were in Joint family. Regarding daily meal pattern, $90 \%$ (18) had three meals per day, $5 \%$ (1) took two meals per day and $5 \%$ (1) took more than 3 meals per day ${ }^{3,11}$. In present study, $15 \%$ (3) had the habits of both smoking and alcoholism, 35\% (7) were smokers and only $15 \%$ (3) were alcoholic, results were almost similar with other studies ${ }^{3,6,10,11}$

Mostly, 45\% (9) had average level of knowledge regarding ischemic heart disease, whereas 35\% (7) had below average and $20 \%$ (4) above average level of knowledge; similar trend was observed in finding from other research. ${ }^{3,4,10,11 .}$ Regarding meaning of Ischemic Heart Disease majority of the patients $70 \%$ (14) answered they don't know, minority of the clients answered 5\% (1) stops the blood supply to the heart.

Regarding changes in Ischemic Heart Disease, majority of clients $80 \%$ (16) answered don't know, minority of clients $10 \%$ (2) answered failure of circulation and infarction. Regarding type of Ischemic Heart Disease, majority of clients 65\% (13) answered hereditary and minority of clients 35\% (7) answered they don't know.

Participants response about Ischemic Heart Disease, majority of clients $40 \%$ (8) answered hypertension, few of clients 5\% (1) answered diabetes ${ }^{3,10}$. Majority $70 \%$ (14) of clients answered high cholesterol diet, as a cause of IHD, similar results were seen in other studies ${ }^{10,12}$ Mostly, $60 \%$ (12) patients replied that obesity causes Ischemic Heart Disease, and few 30\% (6) answered stress can results in heart diseases. Regarding effects of lack of exercises, majority of clients $40 \%$ (8) answered weight gain, minority of clients $15 \%$ (3) answered as they did not know. Majority of clients $85 \%$ (17) were Type-A personality. ${ }^{11}$

\section{Conclusion}

Public awareness of risk factors for ischemic heart disease is essential, but no measures of it exist in India where it is on the rise and the incidence of MI and other cardiac diseases are dramatically increasing. Our study suggests that there is a lack of awareness among a sampled Indian population regarding modifiable risk factors of ischemic heart disease, especially DM, Hypertension. Educational interventions are needed to make the Indian public aware of modifiable risk factors of ischemic heart disease and should specifically target individuals who do not exercise, currently smoke, and have less formal education to be optimally effective as a preventative measure.

\section{Acknowledgement}

The authors wish to acknowledge with gratitude Mr. Rakesh Sharma, Asst. Professor, Himalayan College of Nursing, Dehradun for helping in the preparation of this manuscript.

Contact author via e mail - prasunajelly@gmail.com 


\section{References}

[1]. Rutstein DD, Berenberg W, Chalmers TC, Child CG 3rd, Fishman AP, Perrin EB. Measuring the quality of medical care. A clinical method. N Engl J Med. 1976 Mar 11;294(11):582-8.

[2]. Lopez AD, Mathers CD, Ezzati M, Jamison DT, Murray CJL, eds. Global burden of disease and risk factors. New York, NY: Oxford University Press; 2006.

[3]. Jafary FH, Aslam F, Mahmud H, Waheed A, Shakir M, et al. Cardiovascular health knowledge and behavior in patient attendants at four tertiary care hospitals in Pakistan - a cause for concern. BMC Public Health. 2005;5:124. 1-16

[4]. Khan MS, Jafary FH, Jafar TH, Faruqui AM, Rasool SI, Hatcher J, et al. Chaturvedi. Knowledge of modifiable risk factors of heart disease among patients with acute myocardial infarction in Karachi, Pakistan: a cross sectional study. BMC CardiovascDisord. 2006; 6: 18. http://www.biomedcentral.com/1471-2261/6/18

[5]. Vartiainen E, Puska P, Jousilahti P, Korhonen HJ, Tuomilehto J, Nissinen A. Twenty-year trends in coronary risk factors in north Karelia and in other areas of Finland. Int J Epidemiol. 1994 Jun;23(3):495-504.

[6]. Dowse GK, Gareeboo H, Alberti KG, Zimmet P, Tuomilehto J, et al. Changes in population cholesterol concentrations and other cardiovascular risk factor levels after five years of the non-communicable disease intervention programme in Mauritius. Mauritius Non-communicable Disease Study Group. BMJ. 1995 Nov 11;311(7015):1255-9.

[7]. Lewis SJ. An urgent matter-identifying your patients' cardiovascular risk and improving their outcomes. Low-density lipoprotein cholesterol and coronary heart disease: the importance of reaching target goals with statin therapy. J FamPract. 2009 Nov;58(11 Suppl Urgent):S32-40.

[8]. Lee KK, Lee VW, Chan WK, Lee BS, Chong AC, Wong JC, et al. Cholesterol goal attainment in patients with coronary heart disease and elevated coronary risk: results of the Hong Kong hospital audit study. Value Health. 2008 Mar;11Suppl 1:S91-8. doi: 10.1111/j.1524-4733.2008.00372.x.

[9]. World Health Organization. Facts and figures. The World Health report 2003-shaping the future [online] 2003. Accessed 14 Feb 2005 .

URL: http://www.who.int/whr/2003/en/Facts_and_Figures-en.pdf.

[10]. Fernandez RS ,Salamonson Y, Griffiths R, Juergens C, Davidson P . Awareness of risk factors for coronary heart disease following interventional cardiology procedures: A key concern for nursing practice. International Journal of Nursing Practice. December 2008;14(6):435-442

[11]. Khalid Y, Malina O, Rofiah A, Latinah M, Thahirahtul AZ, Zaridah MS, et al. Disease and risk factor perception among patients with coronary artery disease in Kuala Terengganu. Med J Malaysia. 1994 Sep;49(3):205-8.

[12]. Bairey Merz CN, Felando MN, Klein J. Cholesterol awareness and treatment in patients with coronary artery disease participating in cardiac rehabilitation. J CardiopulmRehabil. 1996 Mar-Apr;16(2):117-22. Available at: http://www.ncbi.nlm.nih.gov/pubmed/8681156 